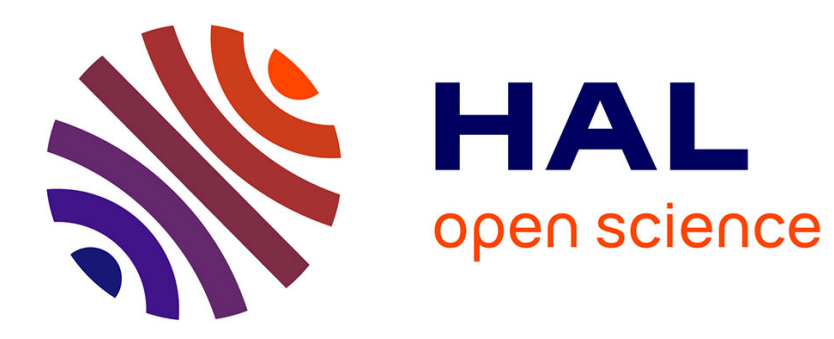

\title{
Simple Stiffness Tailoring of Balsa Sandwich Core Material
}

\author{
J.A. Kepler
}

\section{To cite this version:}

J.A. Kepler. Simple Stiffness Tailoring of Balsa Sandwich Core Material. Composites Science and Technology, 2010, 71 (1), pp.46. 10.1016/j.compscitech.2010.10.002 . hal-00702314

\section{HAL Id: hal-00702314 https://hal.science/hal-00702314}

Submitted on 30 May 2012

HAL is a multi-disciplinary open access archive for the deposit and dissemination of scientific research documents, whether they are published or not. The documents may come from teaching and research institutions in France or abroad, or from public or private research centers.
L'archive ouverte pluridisciplinaire HAL, est destinée au dépôt et à la diffusion de documents scientifiques de niveau recherche, publiés ou non, émanant des établissements d'enseignement et de recherche français ou étrangers, des laboratoires publics ou privés. 


\section{Accepted Manuscript}

Simple Stiffness Tailoring of Balsa Sandwich Core Material

J.A. Kepler

PII:

S0266-3538(10)00375-1

DOI:

10.1016/j.compscitech.2010.10.002

Reference:

CSTE 4821

To appear in:

Composites Science and Technology

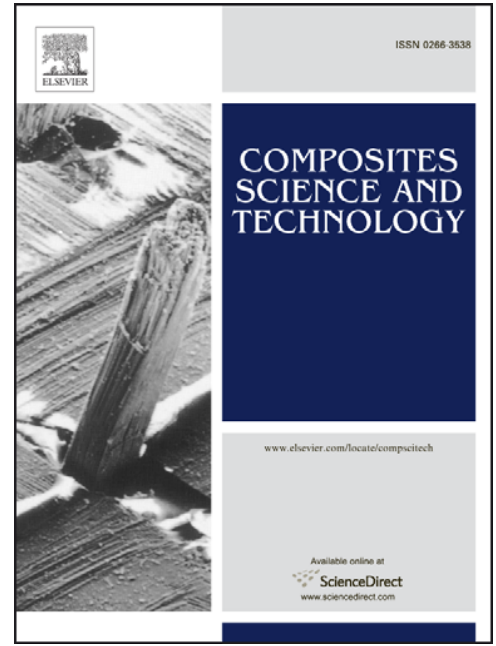

Received Date:

2 March 2010

Revised Date:

27 September 2010

Accepted Date:

3 October 2010

Please cite this article as: Kepler, J.A., Simple Stiffness Tailoring of Balsa Sandwich Core Material, Composites Science and Technology (2010), doi: 10.1016/j.compscitech.2010.10.002

This is a PDF file of an unedited manuscript that has been accepted for publication. As a service to our customers we are providing this early version of the manuscript. The manuscript will undergo copyediting, typesetting, and review of the resulting proof before it is published in its final form. Please note that during the production process errors may be discovered which could affect the content, and all legal disclaimers that apply to the journal pertain. 


\section{SIMPLE STIFFNESS TAILORING OF BALSA SANDWICH CORE MATERIAL}

\section{J. A. Kepler}

Aalborg University, Department of Mechanical Engineering Pontoppidanstraede 101, 9220 Aalborg East, Denmark

jk@me.aau.dk

\section{Abstract}

A concept for improving the shear stiffness properties of balsa core material for sandwich structures is presented. The concept is based on utilization of the strongly orthotropic properties of the balsa wood, applying an appropriate transverse layup sequence. The effective core material shear modulus is modeled using basic laminate theory. This is subsequently validated through sandwich beam bending and lap shear experiments. Compared to the standard balsa core systems, a substantial increase in the shear stiffness is demonstrated, whereas the transverse stiffness is reduced. The concept is suitable for mass production, using standard plywood fabrication technology.

Keywords: B: Mechanical properties, C: Elastic properties, $C$ : Sandwich structures, $C$. Laminate theory, Balsa wood core

\section{INTRODUCTION}

Balsa wood is frequently used for core material in sandwich structures, due to the favorable stiffness/weight ratio. Descriptions of the general use of balsa wood in sandwich structures may be found in standard handbooks, such as [1] by Zenkert. It is usually oriented with the grain-direction normal to the extension plane of a sandwich panel - one reason for this is retardation of decomposition due to moisture in case of a 
face-sheet puncture. Also, the high axial (along the grain) stiffness of balsa wood improves the resistance of the sandwich panel to local indentations and face-sheet wrinkling and dimpling. In a recent study by Tagarielli et al. [2], the axial compression properties were shown to be highly strain-rate sensitive, providing a significant increase in dynamic strength compared to the quasi-static behavior. Furthermore, the study demonstrated, in agreement with several previous studies, that the axial compressive strength properties are clearly superior to those of PVC foams of comparable densities. However, the orientation of the axial direction transverse to the sandwich panel plane gives a poor utilization of the orthotropic properties of the wood with respect to the transfer of transverse (shear) force through the core, and makes the core prone to sudden transverse splitting. A concept for improving the stiffness using balsa elements was presented by Bekisli and Grenestedt [3].This provided an improved shear stiffness in two primary transverse planes, but required elaborate machining of the balsa elements. Conceptually, the use of balsa wood in such applications is similar to any periodical distribution of a highly orthotropic material, in order to obtain desirable properties. In the extreme case, an orthotropic material may be approximated by a unidirectional strut, where, of course, the sandwich panel core becomes a truss web structure. A paper by Liu et al. [4] elaborates on homogenization of properties for these types of core; the relative performance, as compared to other sandwich core concepts, was studied by Wicks and Hutchinson ([5] and [6]).

\section{Simplified Concept}

The concept presented here provides an improvement of the shear properties, particularly the effective core shear modulus $\mathrm{G}_{\mathrm{xy}}$. It will be effective in only one 
transverse plane, but is straightforward and economically feasible. The principle is illustrated in figure 1.

a)

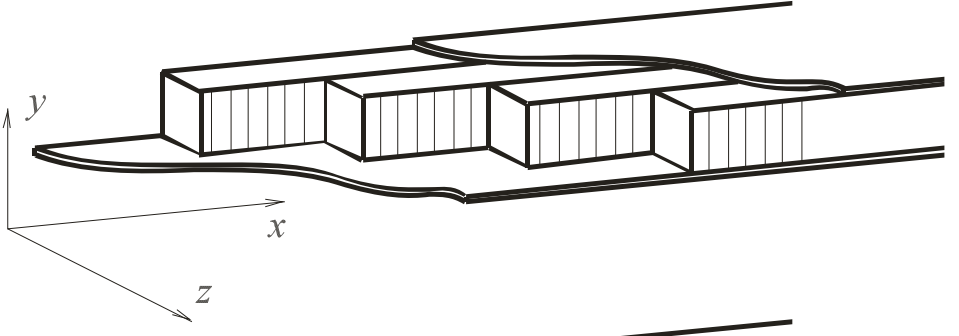

b)

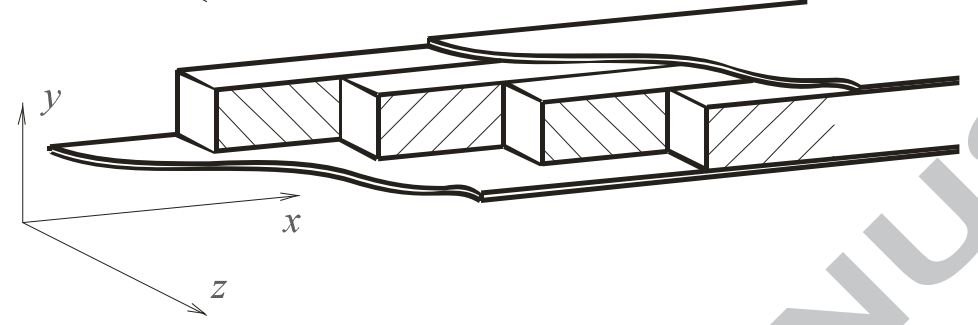

Fig. 1: Comparison (balsa wood fiber direction indicated by thin-line hatching) between: a: ordinary arrangement, b: stacking for improved core shear stiffness in the xy-plane

As indicated in figure 1 , the chosen coordinate axes in the present study deviate from the standard notation for sandwich panels, where the transverse direction is habitually designated z. In the present study, the primary factor of interest is the effective core shear modulus, and, as indicated below, prediction thereof may conveniently be done by classical laminate theory, where $\mathrm{z}$ indicates the stacking direction. In other words, the core material is considered as a laminate with stacking direction along one of the plane directions of the sandwich panel.

The core manufacturing parameters for the present study are outlined in figures 2 and 3. Thin plates (thickness $\mathrm{b}=5 \mathrm{~mm}$ in the present study) of balsa wood are cut at an angle 
$\alpha$ to the grain direction. In the present examination, three values have been investigated, $\alpha=90^{\circ}, 67.5^{\circ}, 45^{\circ}$, as indicated in figure 2 .

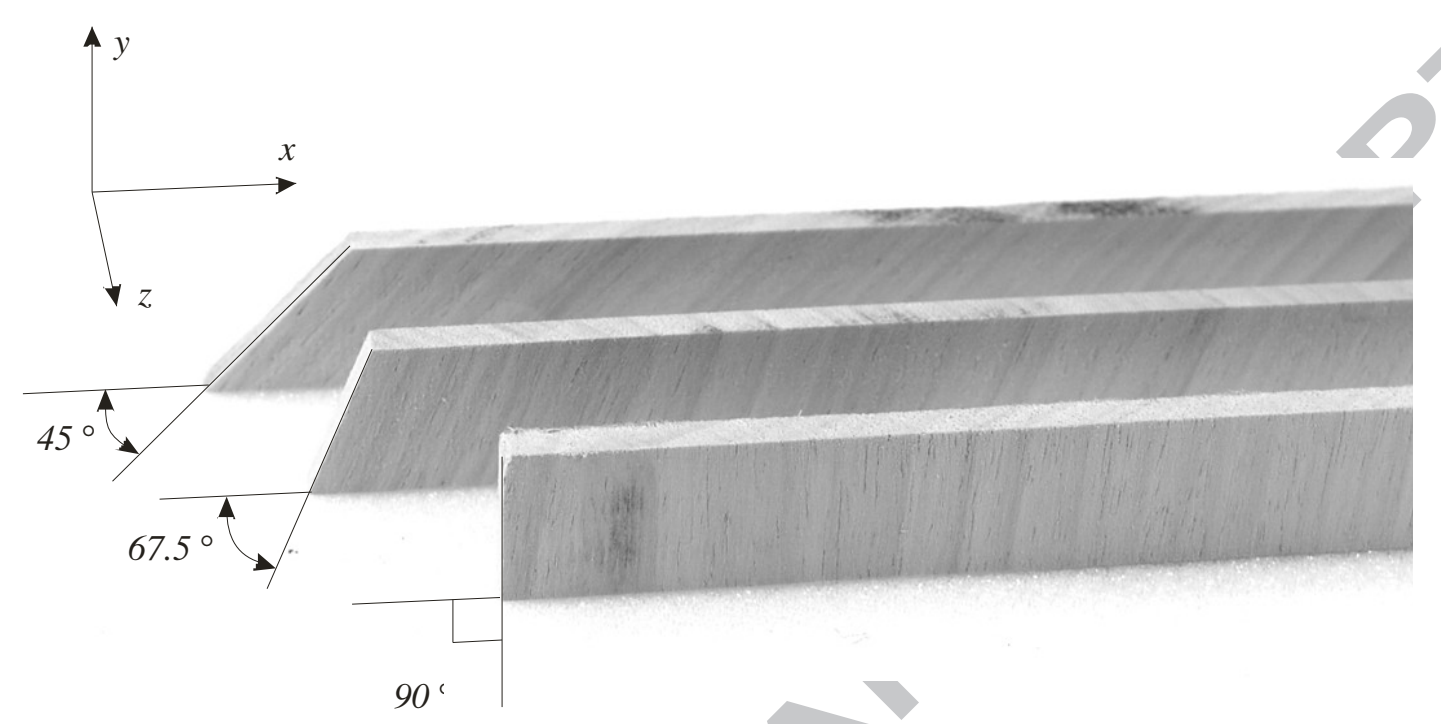

Fig. 2: Balsa elements at different plane-to-grain angles $\alpha$.

Subsequent cuts are separated a distance $\mathrm{H}_{\mathrm{c}}$ corresponding to the desired core material thickness. The pre-cut elements are then stacked at alternating angles $\pm \alpha$ to provide a core beam or plate. The stacking sequence may be arbitrary, but in the present study, angles $\alpha$ are kept constant in any given specimen or model as exemplified in figure 3 .

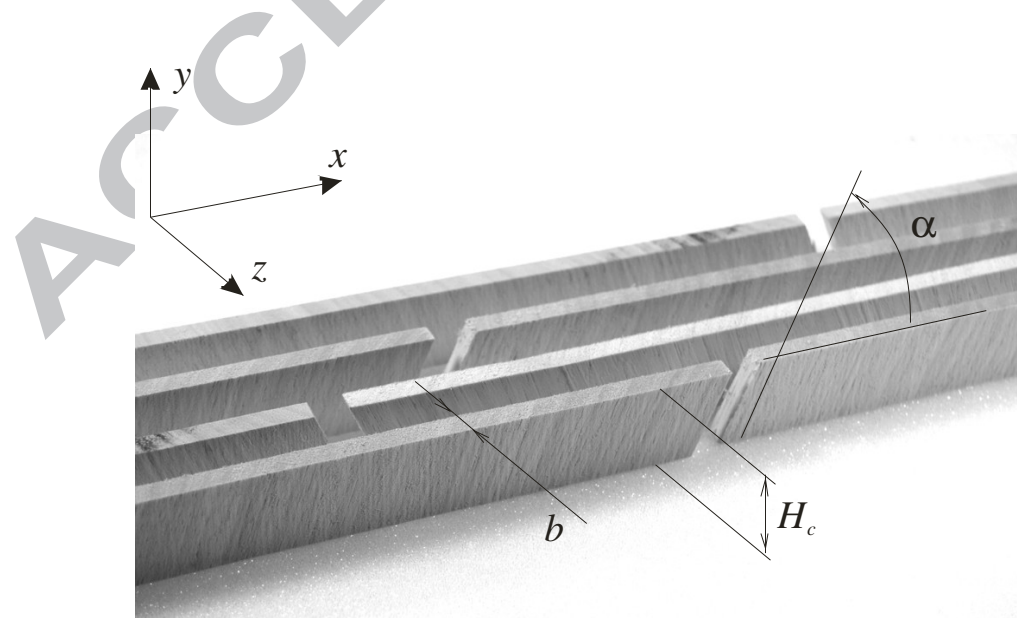


Fig. 3: Stacking of balsa elements, height $\mathrm{H}_{\mathrm{c}}$ and width $\mathrm{b}$ at alternating angles $\pm \alpha$. Note the staggering so that joints are distributed.

The balsa plates were purchased through a modeling supplies retailer and matched to provide the best possible consistence ( 6 plates, $121 \mathrm{~kg} / \mathrm{m}^{3}<\rho<138 \mathrm{~kg} / \mathrm{m}^{3}$ ). In most practical cases, the density variation may be considerably larger.

\section{PARAMETERS FOR PREDICTION OF SHEAR STIFFNESS}

Through the use of classical (plane) laminate theory (see e.g. Jones [7]), the effective shear modulus may be calculated for a stacked balsa core at a given stacking sequence. The individual lamina may be constitutively described for a given angular orientation through transformation of the principal-axis constitutive relation:

$$
\left\{\begin{array}{l}
\sigma_{1} \\
\sigma_{2} \\
\tau_{12}
\end{array}\right\}=\left[\begin{array}{ccc}
Q_{11} & Q_{12} & 0 \\
Q_{21} & Q_{22} & 0 \\
0 & 0 & Q_{66}
\end{array}\right]\left\{\begin{array}{l}
\varepsilon_{1} \\
\varepsilon_{2} \\
\gamma_{12}
\end{array}\right\}=[Q]\left\{\begin{array}{c}
\varepsilon_{1} \\
\varepsilon_{2} \\
\gamma_{12}
\end{array}\right\}
$$

where, due to symmetry, $\mathrm{Q}_{12}=\mathrm{Q}_{21}$. The formulation is reduced from the full 3Dformulation, under the assumption that out-of-plane effects are insignificant. For the present case, it means that the analysis is invalid for the yz-plane core shear stiffness.

The components of the constitutive matrix, in terms of engineering constants are found as 
$Q_{11}=\frac{E_{1}}{1-v_{12} v_{21}}$ and $Q_{22}=\frac{E_{2}}{1-v_{12} v_{21}}$

$Q_{12}=Q_{21}=\frac{v_{21} E_{1}}{1-v_{12} v_{21}}=\frac{v_{12} E_{2}}{1-v_{12} v_{21}}$ and $Q_{66}=G_{12}$

In the arbitrary orientation, the constitutive relation is found through

$$
\left.\left\{\begin{array}{l}
\sigma_{x} \\
\sigma_{y} \\
\tau_{x y}
\end{array}\right\}=\left[\begin{array}{lll}
\bar{Q}_{11} & \bar{Q}_{12} & \bar{Q}_{16} \\
\bar{Q}_{21} & \bar{Q}_{22} & \bar{Q}_{26} \\
\bar{Q}_{61} & \bar{Q}_{62} & \bar{Q}_{66}
\end{array}\right]\left\{\begin{array}{l}
\varepsilon_{x} \\
\varepsilon_{y} \\
\gamma_{x y}
\end{array}\right\}=[\bar{Q}]\right\}\left\{\begin{array}{c}
\varepsilon_{x} \\
\varepsilon_{y} \\
\gamma_{x y}
\end{array}\right\}=[T]^{-1}[Q][T]^{-T}\left\{\begin{array}{l}
\varepsilon_{x} \\
\varepsilon_{y} \\
\gamma_{x y}
\end{array}\right\}
$$

where again the constitutive matrix is symmetric, and [T] is the transformation matrix.

The derivation may be found in [7], but is summarized here for completeness.

For the present subject, the term of particular interest is $\bar{Q}_{66}$, which directly links shear strain and stress. In this capacity, it will be a direct measure of the shear stiffness of the core material at arbitrary angles $\alpha$, and will be referred to as the effective shear modulus $\mathrm{G}_{\mathrm{xy}}$.

The $\bar{Q}_{22}$ term, being a measure of the transverse stiffness, is of relevance in areas of high transverse load intensity, where core indentation may be an issue, and in suppression of compressive face-sheet wrinkling. Deviation from the typical fibre angle $\left(\alpha=90^{\circ}\right)$ will lead to an increasing effective shear modulus, but this will be gained at the expense of transverse compressional stiffness. In this sense, the specific core layup 
configuration must be a compromise, dictated by the proportions of global shear load, local transverse load intensity and pure bending.

\section{Engineering stiffness constants $E_{1}, E_{2}, v_{12}, G_{12}$}

As implied, the elementary properties of the balsa wood in the principal material coordinates (axial, radial and tangential for wooden materials) must be measured or estimated through empirical formulas, for use in the laminate theory expressions. Properties in the radial and tangential directions are, by necessity, averaged, since the lengthwise sawing orientation of the balsa wood is variable; the approximate average modulus is referred to as the transverse modulus.

In the book by Gibson and Ashby [8], readily available formulas for the stiffness constants are presented, and it is relevant to use these. However, this leads to a brief digression, as the formulas suggested in [8] are evaluated against the directly and indirectly available experimental data. The approximate chronological progression is recorded in table 1.

Initially, the formulas (given in row a in table 1) were used to produce data for the specific balsa wood (row $\mathbf{b}$ in table 1 ). Clearly, the dominant factors are $\mathrm{E}_{1}$ and $\mathrm{G}_{12}$. Using classical laminate theory, the dependence of the apparent shear modulus $G_{x y}$ on the angle $\alpha$ is shown in figure 4 and in the final comparison, presented in figure 11 . The transverse modulus $\mathrm{E}_{2}$ seemed unrealistically low, and direct measurements on the 5 mm thick balsa plates was impractical. Therefore, measurements were performed on a larger plank of balsa wood. For this specimen, the density was $78 \mathrm{~kg} / \mathrm{m}^{3}$, and the primary extensional moduli were measured (row $\mathbf{c}$ in table 1). These were compared with corresponding predicted values (row $\mathbf{d}$ in table 1), and the formulas were adjusted 
accordingly (row $\mathbf{e}$ in table 1); in particular, the exponent 3 in the original expression for $\mathrm{E}_{2}$ was adjusted to 2.3 , producing an acceptable fit for the $78 \mathrm{~kg} / \mathrm{m}^{3}$ specimen.

A direct measurement of the shear modulus $\mathrm{G}_{12}$ for the $129 \mathrm{~kg} / \mathrm{m}^{3}$ balsa was obtained by a lap shear experiment (see below), and used in the modeling. An indirect measurement, by 3 point bending of a sandwich beam (see below), gave a value of $147 \mathrm{MPa}$.

\begin{tabular}{|c|c|c|c|c|}
\hline & $\begin{array}{l}\text { Axial modulus } \\
\mathrm{E}_{1}[\mathrm{MPa}]\end{array}$ & $\begin{array}{l}\text { Transverse } \\
\text { modulus } \\
\mathrm{E}_{2}[\mathrm{MPa}]\end{array}$ & $\begin{array}{l}\text { Poisson's ratio } \\
\mathrm{v}_{12}[]\end{array}$ & $\begin{array}{l}\text { Shear Modulus } \\
\mathrm{G}_{12}[\mathrm{MPa}]\end{array}$ \\
\hline a): [8] & $\frac{\rho}{\rho_{s}} E_{s}$ & $C\left(\frac{\rho}{\rho_{s}}\right)^{3} E_{s}$ & $0.23-0.49$ & $0.074 \frac{\rho}{\rho_{s}} E_{s}$ \\
\hline $\begin{array}{l}\text { b): [8], with } \\
\rho=129 \mathrm{~kg} / \mathrm{m}\end{array}$ & 3010 & $12-18$ & $0.23-0.49$ & 223 \\
\hline $\begin{array}{l}\text { c): Measured } \\
\rho=78 \mathrm{~kg} / \mathrm{m}^{3}\end{array}$ & 1630 & 26.5 & N/A & N/A \\
\hline $\begin{array}{l}\text { d): [8], with } \\
\rho=78 \mathrm{~kg} / \mathrm{m}^{3}\end{array}$ & 1820 & $2.7-3.9$ & $0.23-0.49$ & 134 \\
\hline
\end{tabular}




\begin{tabular}{|l|l|l|l|l|}
\hline e): [8] adjusted & $\frac{\rho}{\rho_{s}} E_{s} \cdot \frac{1630}{1820}$ & $C\left(\frac{\rho}{\rho_{s}}\right)^{2.3} E_{s}$ & $0.23-0.49$ & N/A \\
\hline f): Lap shear & N/A & $\mathrm{C}=0.54-0.8$ & & \\
test with $\rho=$ & N/A & N/A & 134 \\
$129 \mathrm{~kg} / \mathrm{m}^{3}$ & & & & \\
\hline
\end{tabular}

Table 1: Derivation of engineering stiffness constants. In all formulas:

cell wall density $\rho_{\mathrm{s}}=1500 \mathrm{~kg} / \mathrm{m}^{3}$ and axial cell wall modulus $\mathrm{E}_{\mathrm{s}}=35 \mathrm{GPa}$ ([8])

Using the expressions in table 1 row $\mathbf{e}$, the following engineering constants are predicted for $\rho=129 \mathrm{~kg} / \mathrm{m}^{3}: \mathrm{E}_{1}=2700 \mathrm{MPa}, \mathrm{E}_{2}=83 \mathrm{MPa}(67-99 \mathrm{MPa}), \mathrm{v}_{12}=0.35$. The shear modulus as measured directly through a lap shear experiment on the relevant material density, yielded $\mathrm{G}_{12}=134 \mathrm{MPa}$ (table 1 row $\mathbf{f}$ ). For a detailed account of the experimental procedure, see below.

Using these data, results for the laminate theory predictions are given in figure 4 for the transverse compression $\left(\bar{Q}_{22}\right)$ and shear $\left(\bar{Q}_{66}\right)$ stiffnesses, as these quantities are of primary importance in sandwich core materials. In figure 4 , tilde $(\sim)$ is used to indicate transformed properties as opposed to principal stiffnesses (e.g. Q 66 $=\bar{Q}_{66}$ ). 


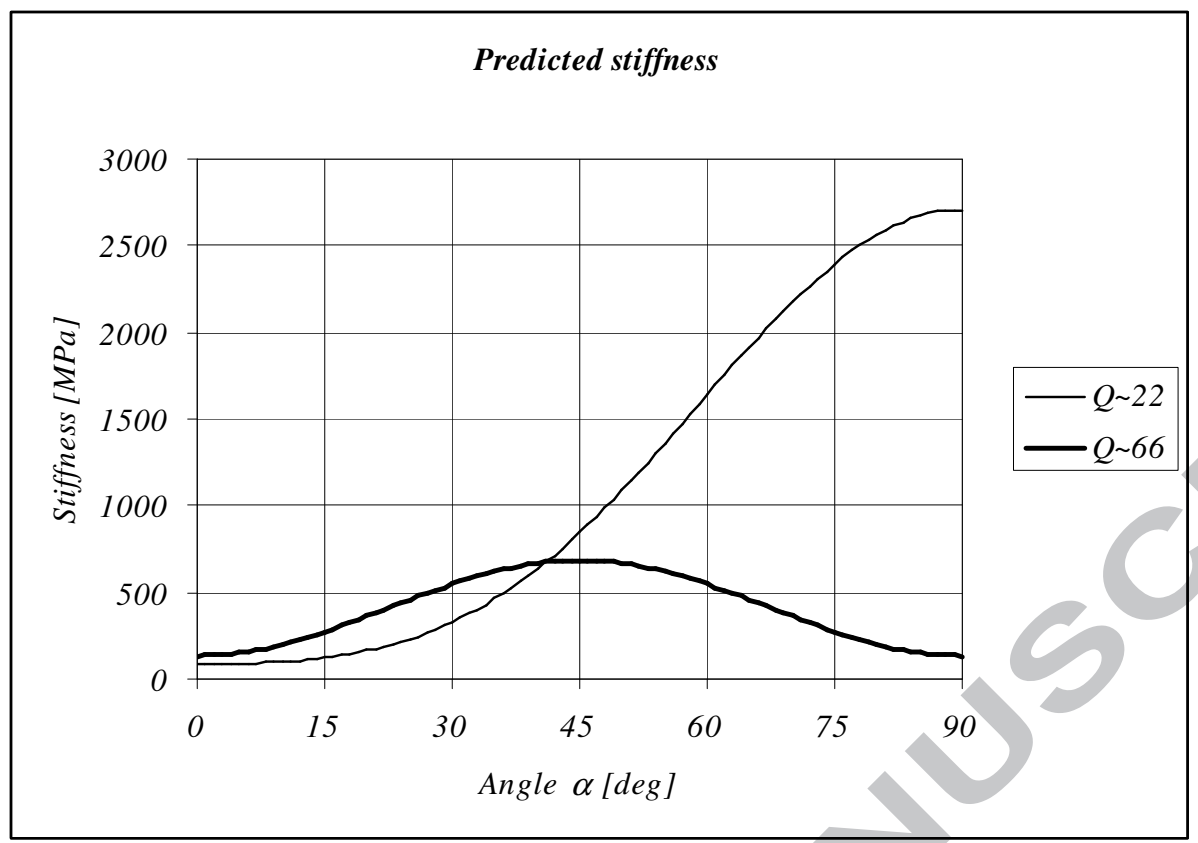

Fig. 4: $\bar{Q}_{22}, \bar{Q}_{66}$-components of the stiffness matrix for a single "ply" of balsa wood, shown for angles $0^{\circ} \leq \alpha \leq 90^{\circ}$.

One notes the expected dependence on the layup angle $\alpha$. .

\section{EXPERIMENTAL INVESTIGATION}

For verification of the predicted shear stiffness, simple lap shear experiments and 3point sandwich beam bending experiments were conducted.

\section{Preparation of Test Specimens}

In the present investigation, the parameters 
$\mathrm{H}_{\mathrm{c}}=20 \mathrm{~mm}, \mathrm{~b}=5 \mathrm{~mm}$

were kept constant. The specimens used for the experimental verifications invariably consisted of six layers with a stacking sequence of $[ \pm \alpha]_{3}$. For specimens where $\alpha \neq$ $90^{\circ}$, this introduces a small amount of shear/twist coupling, which is ignored in the following.

For manufacture of a specimen, strips of balsa wood were cut at the appropriate angle from $5 \mathrm{~mm}$ thick plates of balsa wood, with a strip width slightly larger than the final core height (22 $\mathrm{mm}$ for a final core height $\mathrm{H}_{\mathrm{c}}=20 \mathrm{~mm}$ ). The six layers for a given specimen were then bonded together using a PVA wood glue (Akzo Nobel, Cascol 3301). The glue was diluted with water (1:1 by volume), for facilitation of the glue application (using a painting brush). After adhesion, the specimens were left to dry at room temperature for one week, whereupon the specimens were trimmed to the final height.

Face sheets for sandwich beam specimens were cut from mild steel plate:

Thickness $\mathrm{t}_{\mathrm{f}}=1 \mathrm{~mm}$, width $\mathrm{B}=6 \mathrm{~b}=30 \mathrm{~mm}$, modulus $\mathrm{E}_{\mathrm{f}}=210 \mathrm{Gpa}$

Immediately prior to bonding of the face sheets to the core, the face sheets were lightly bead-blasted and degreased using acetone. For bonding sandwich face sheets or lap shear bars to the core specimens, an epoxy adhesive (Araldite 2011) was used. The specimens were kept under pressure for 24 hours after adhesive assembly, then left to post-cure for another 24 hours, i.e. 48 hours at room temperature.

\section{Lap shear experiments}


The shear stiffness for two configurations $\left(\alpha=90^{\circ}, 45^{\circ}\right)$ was investigated using a standard lap shear test. The experimental setup is shown in figure 5.

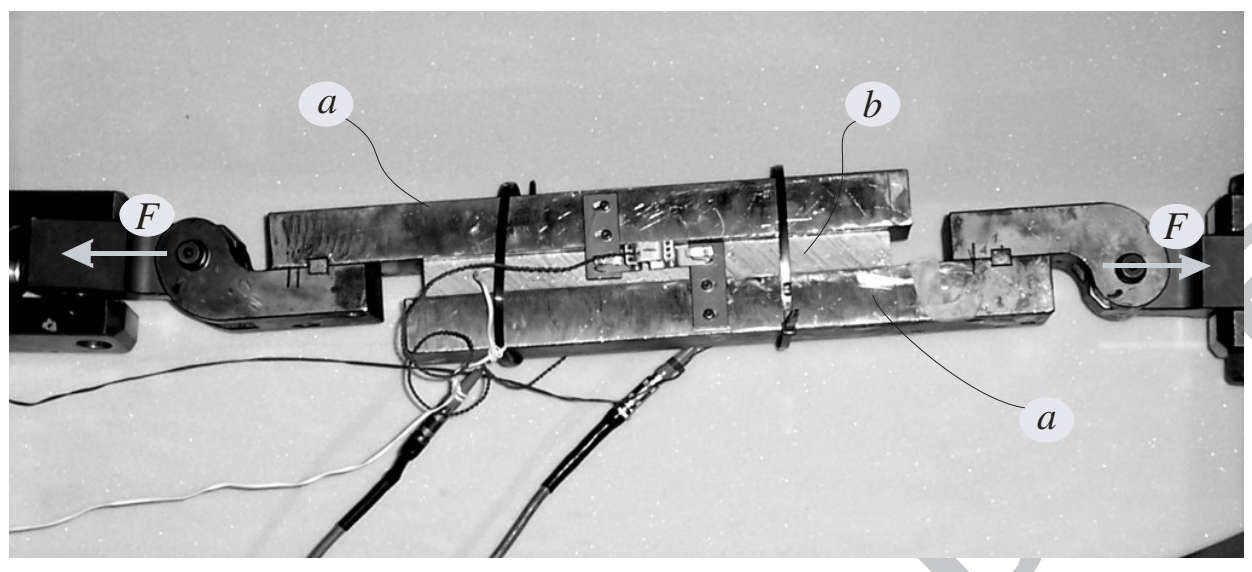

Fig. 5: Lap shear test setup. The parts are: $a$ - steel shear bars, $b$ - shear specimen

In figure 5, the test setup is shown with an $\alpha=45^{\circ}$ specimen. The small angle between the specimen extension direction and the line of action of the forces $\mathrm{F}$ is ignored. A high-sensitivity clip gauge measures the relative motion between the steel shear bars.

The specimen dimensions were: length $\mathrm{L}=240 \mathrm{~mm}$, width $\mathrm{B}=30 \mathrm{~mm}$, height $\mathrm{H}_{\mathrm{c}}=20$ $\mathrm{mm}$

One weakness of the lap shear tests, as the one illustrated in figure 5, is that a uniform shear stress over the length of the specimen cannot be fulfilled near the free edges of the specimen. In the present case, the balsa core material is highly orthotropic, with the direction of maximum stiffness of the individual core-layer indicated by the angle $\alpha$, and a specimen length detriment has been introduced, according to figure 6 . 


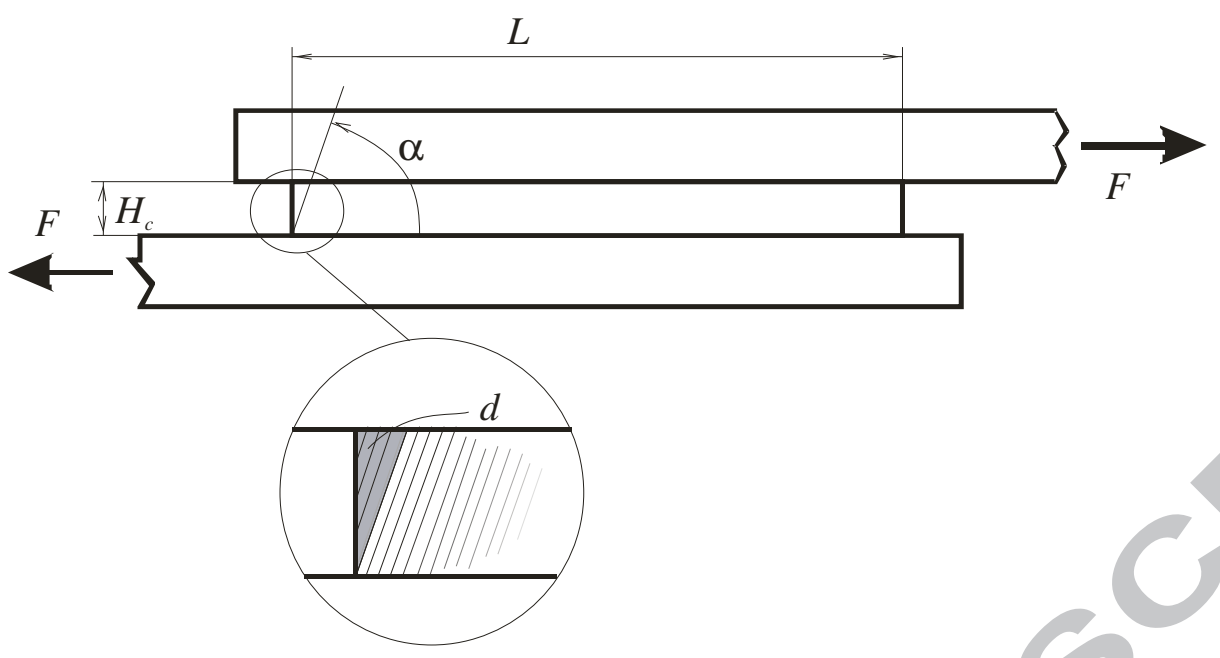

Fig. 6: Determination of length detriment according to the specimen grain direction, where the shaded area $d$ is ignored for the purpose of assessing the shear stiffness $G_{x y}$.

Therefore, referring to figure 6 , an area $\mathrm{d}$ at each end of the specimen is considered ineffective for transferring the shear stress in the specimen. The length of the specimen is, for the purpose of calculating the shear stress, reduced correspondingly (by $20 \mathrm{~mm}$ for the $\alpha=45^{\circ}$; no reduction for $\alpha=90^{\circ}$ ), producing representative lengths:

$\mathrm{L}_{\text {rep }}\left(\alpha=45^{\circ}\right)=220 \mathrm{~mm}$

$\mathrm{L}_{\text {rep }}\left(\alpha=90^{\circ}\right)=240 \mathrm{~mm}$

The results of the lap shear tests are shown in figure 7 . 


\section{Lap shear test results}

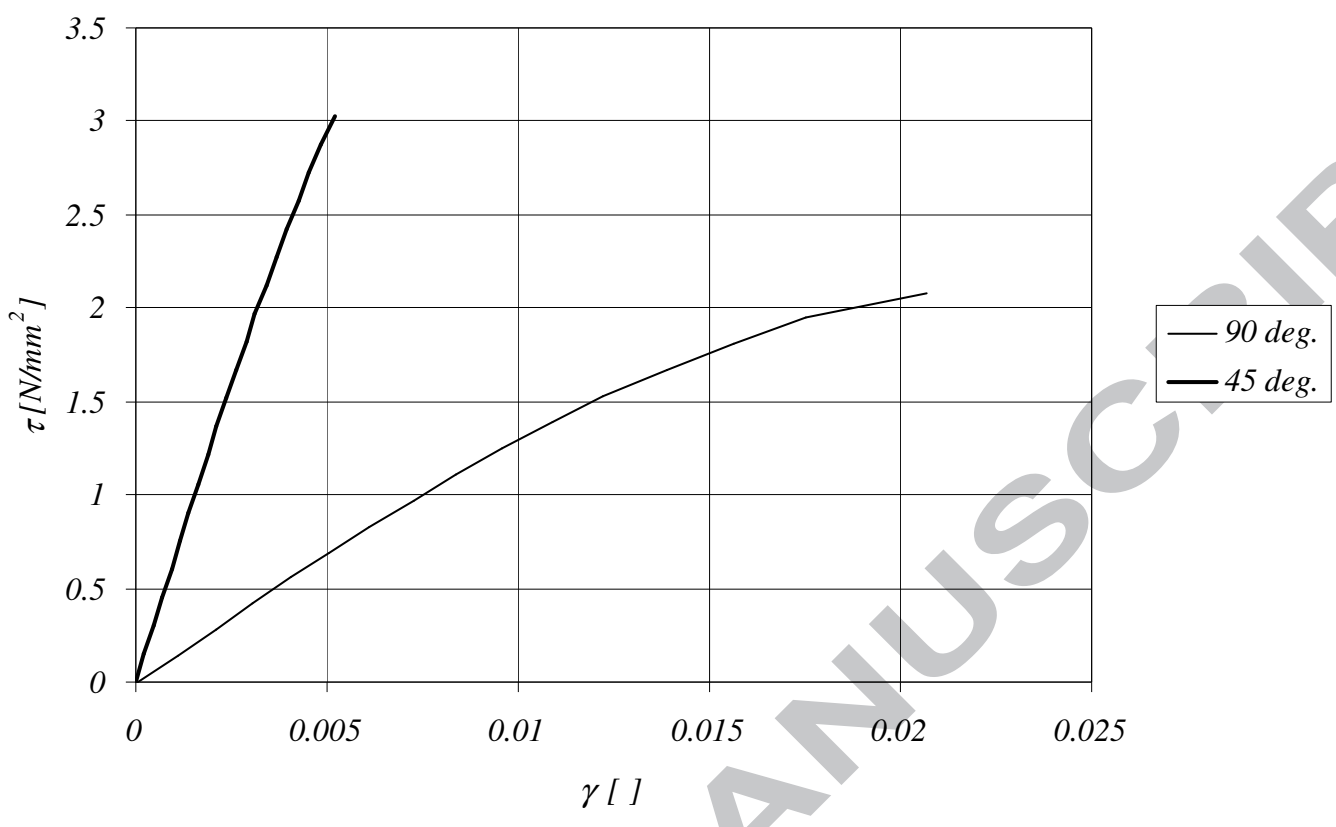

Fig. 7: Shear stress/strain curves for specimens with $\alpha=90^{\circ}$ and $45^{\circ}$.

Calculation of the effective shear modulus is done as follows:

$$
\tau=G_{x y} \cdot \gamma=\frac{F}{L_{r e p} \cdot B} \Rightarrow G_{x y}=\frac{F}{L_{r e p} \cdot B \cdot \gamma}
$$

where: F: shear force (see figure 6)

$\mathrm{L}_{\text {rep }}$ : representative length, as discussed above,

B: specimen width

$\gamma$ : shear strain

The shear strain $\gamma$ is, for small deformations, calculated by 
$\gamma=\Delta / H_{c}$

where D: lap shear plate displacement (as measured using clip gauges, see figures 5,6)

$\mathrm{H}_{\mathrm{c}}$ : specimen height

The corresponding effective shear moduli, derived from the lap shear experiments as the limit secant moduli for $\gamma \rightarrow 0$, were: $\mathrm{G}_{\mathrm{xy}}\left(\alpha=45^{\circ}\right)=655 \mathrm{Mpa}, \mathrm{G}_{\mathrm{xy}}\left(\alpha=90^{\circ}\right)=134 \mathrm{Mpa}$

\section{Sandwich beam experiments}

As mentioned above, the free edges of the lap shear test specimens introduce a zone of nonuniform shear stress. For compensation, the representative length of the specimen was reduced according to the orthotropic characteristics of the specimen. For a separate verification of the core properties, sandwich beam specimens subjected to symmetrical 3-point bending were studied, using stacked balsa core at three different angles $(\alpha=$ $\left.90^{\circ}, 67.5^{\circ}, 45^{\circ}\right)$. The beam geometry is shown in figure 8 .

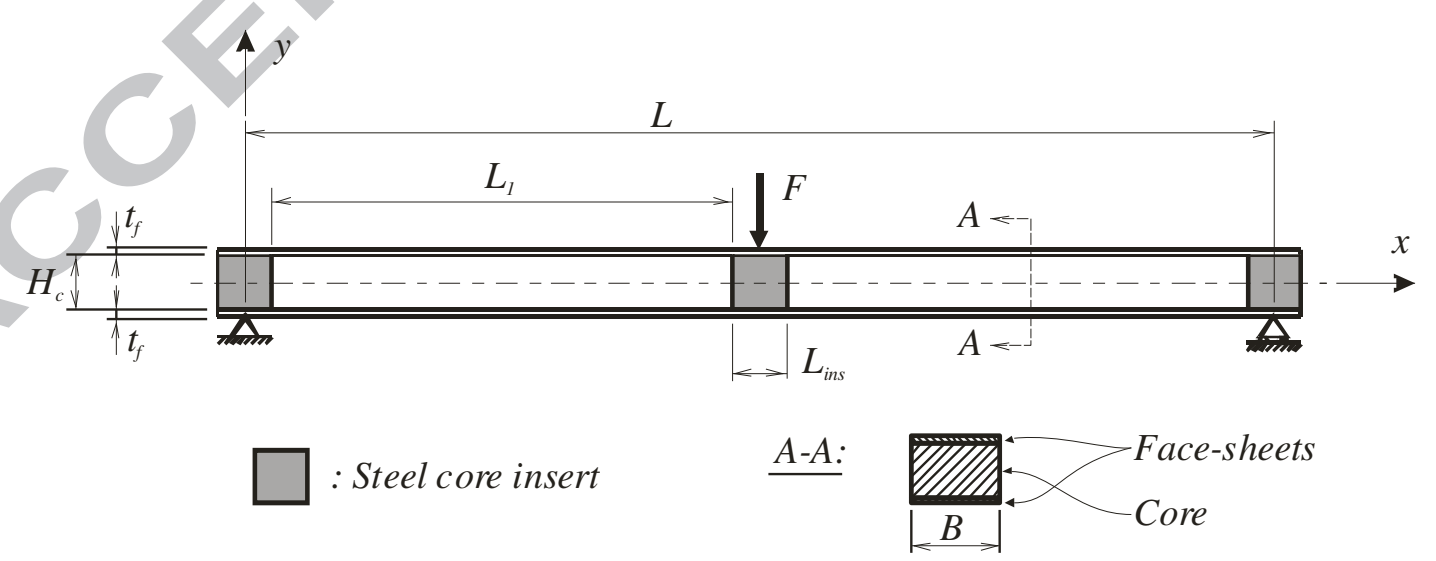


Fig. 8: Sandwich beam specimen. $L=300 \mathrm{~mm}, \mathrm{~L}_{1}=130 \mathrm{~mm}, \mathrm{~L}_{\mathrm{ins}}=20 \mathrm{~mm}, \mathrm{~B}=30$ $\mathrm{mm}, \mathrm{H}_{\mathrm{c}}=20 \mathrm{~mm}, \mathrm{t}_{\mathrm{f}}=1 \mathrm{~mm}$

As indicated in figure 8, core inserts of steel were used at the load introduction locations in order to obtain negligible core compression. The face-sheets were manufactured from $1 \mathrm{~mm}$ thick steel plate.

The test was performed in a $20 \mathrm{kN}$ test machine with the specimen supported on a moving crosshead, as shown in figure 9.

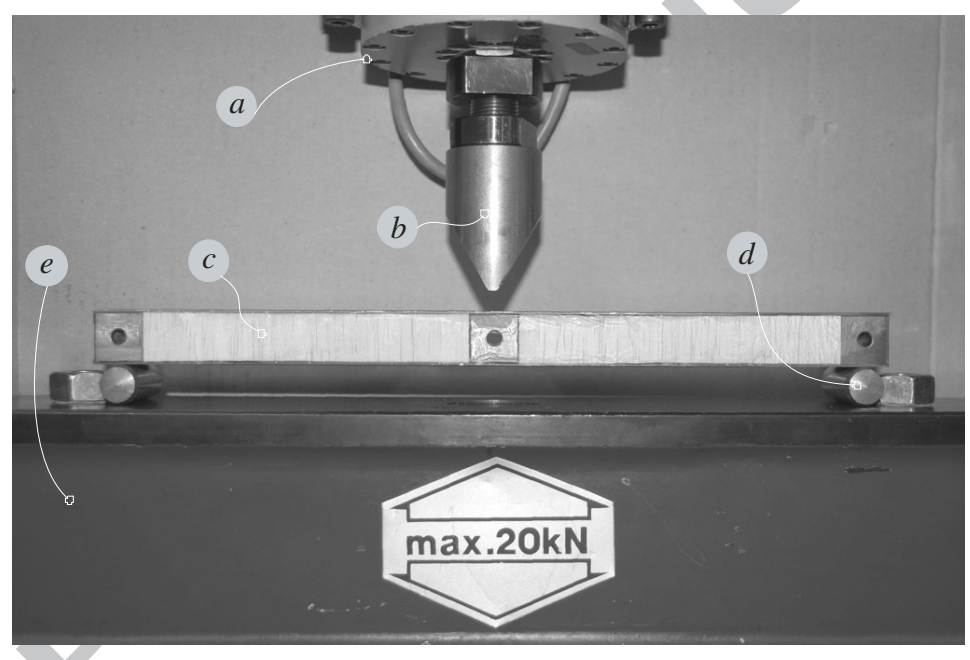

Fig. 9: Closeup picture of 3-point sandwich beam bending test, showing:

a: load cell, b: central loading tup, c: sandwich beam specimen with load introduction inserts at the endpoints and the middle, d: support rollers, e: crosshead

Prior to the recorded test results (see below), the specimens were loaded moderately (to $500 \mathrm{~N}$ ) and unloaded to verify the specimen / support fit. In figure 10, the force/displacement relations for six tests are shown. 


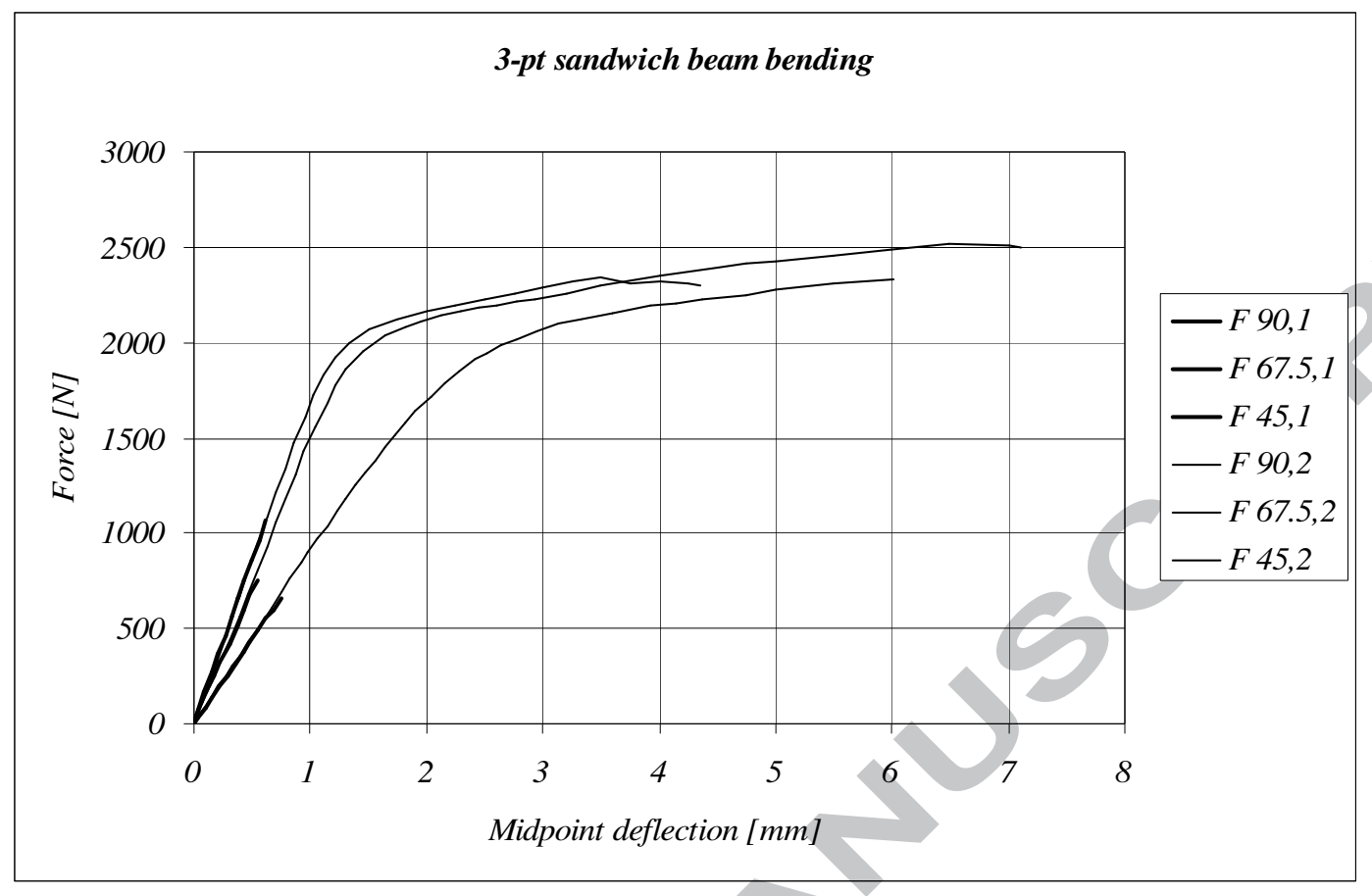

Fig. 10: Force / deflection curves for three-point sandwich beam bending tests. F $\alpha$,\# indicates the \#th test of a specimen with core angle $\alpha$.

In the first three tests ( $\#=1$ ) in figure 10 , the specimens were moderately loaded to provide data for the specimen compliances. In the second three tests $(\#=2)$, the specimens were loaded to failure.

Of immediate interest, the failure strength varies only moderately between the three specimens, with a nominal failure shear stress $\tau_{\text {fail }}$ between 3.8 and 4.2 MPa. However, all three failed specimens exhibited failure in the interface between the core and the face-sheets, where the interface bond rather than the core strength has been the determining factor. As the present investigation deals primarily with the shear stiffness, this is of secondary importance. 
Using first order shear deformation theory (FOSDT), the measured specimen compliance was compared with a calculated compliance, with the shear stiffness $G_{x y}$ of the core material as the single unknown quantity.

The apparent shear stiffnesses were

$\mathrm{G}_{\mathrm{xy}}\left(\alpha=45^{\circ}\right)=670 \mathrm{Mpa}, \mathrm{G}_{\mathrm{xy}}\left(\alpha=67.5^{\circ}\right)=350 \mathrm{Mpa}, \mathrm{G}_{\mathrm{xy}}\left(\alpha=90^{\circ}\right)=147 \mathrm{Mpa}$

\section{COMPARISON OF RESULTS}

In figure 11 , predicted values of the apparent shear modulus $G_{x y}$ are presented alongside the values inferred from the experiments, corresponding to the test specimen range of angles $\alpha$.

\section{Comparison of results}

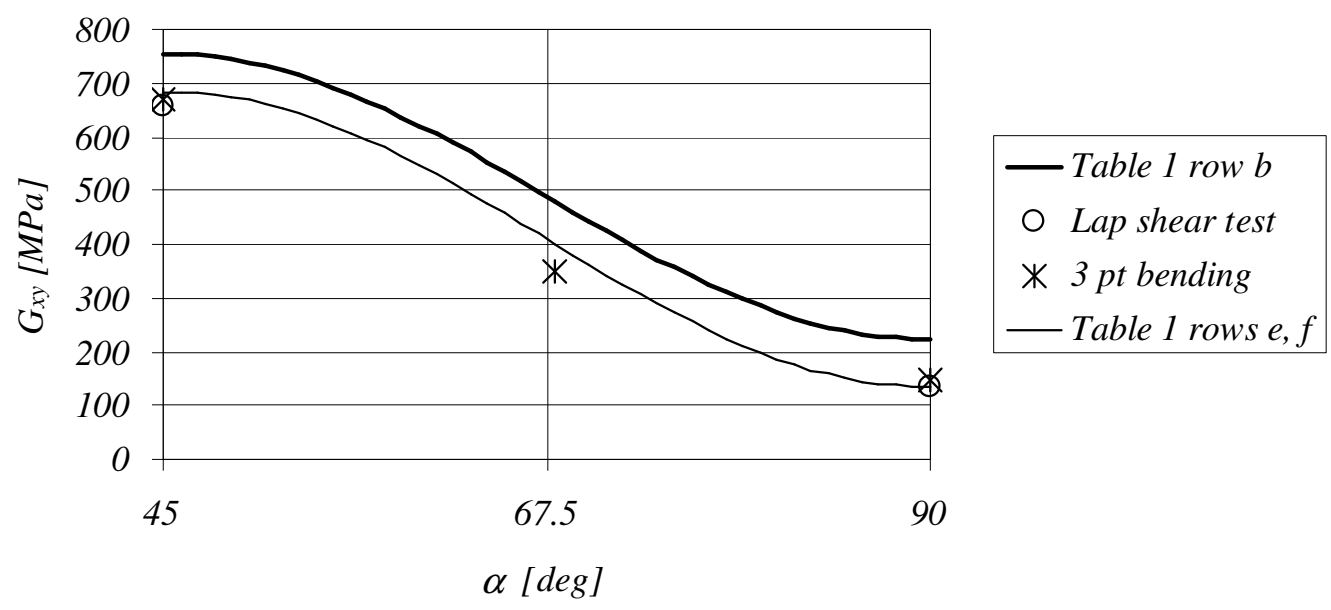

Fig. 11: Comparison of apparent shear modulus $\mathrm{G}_{\mathrm{xy}}(\alpha)$ found by: laminate theory with material properties estimated according to [8], lap shear test, sandwich beam 3-point 
bending test and, finally, laminate theory using material parameters measured or found through modified versions of formulas suggested in [8].

When using base orthotropic properties predicted directly according to [8], the level of shear stiffness is substantially and consistently higher than the measured values.

Instead, the values measured directly or extrapolated from measured data may be used:

$\mathrm{E}_{1}=2700 \mathrm{MPa}, \mathrm{E}_{2}=83 \mathrm{MPa}, \mathrm{G}_{12}=134 \mathrm{Mpa}, \mathrm{v}_{12}=0.35(0.23-0.49)$

and one obtains a better agreement.

At $\alpha=90^{\circ}$, where the direct result for the lap shear test was used as input for the laminate theory model, the agreement between theory and experimental data must obviously be good. In the intermediate range, specifically comparing the result from 3point sandwich beam bending at $\alpha=67.5^{\circ}$ with the prediction from laminate theory, the agreement is less convincing, but still within reasonable limits.

\section{DISCUSSION AND CONCLUSIONS}

The results of the modeling and measurements are not in full agreement - one reason may be found in the Love-Kirchoff assumptions of classical laminate theory which state that deformation-, strain- and stress-effects out of the stacking plane may be ignored.

With the thickness $(b=5 \mathrm{~mm})$ and the relative softness of the balsa core "plies", these assumptions may not permit an adequate description of the deformation state.

Applying First-Order Shear Deformation Theory (FOSDT) for extracting the shear modulus in the 3-point bending tests, the shear stress distribution was assumed uniform 
across the core. Furthermore, the assumptions of a simple FOSDT are not properly satisfied in the transition region between steel inserts and balsa core; the face-sheet shear stiffness contribution can not be ignored completely. This, as expected, produces a higher apparent shear stiffness as compared to the lap shear test value.

The use of formulas from "Cellular Solids" by Gibson and Ashby [8] necessitated some elaboration on the appropriateness of said formulas - in particular, prediction of the transverse modulus deviated significantly from the measurable values. This formula is based on representation of the cell wall deformation by idealized beam-bending (hence the exponent 3), which may not be appropriate. Only a moderate amount of experimental data is available in the low-density range ([8], figure 10.12), and the scatter is considerable.

The method of manufacture involved diluted PVA glue. It may be that the exposure to excess moisture degraded the mechanical properties of the balsa wood (see e.g. [9]). However, as the balsa wood is relatively open for diffusion and was stored in a dry room at room temperature for one week after core manufacture, this is deemed unlikely. The measured apparent shear stiffnesses were 134-147 $\mathrm{MPa}$ for $\alpha=90^{\circ}, 350 \mathrm{MPa}$ for $\alpha$ $=67.5^{\circ}$ and 655-670 MPa for $\alpha=45^{\circ}$, indicating an approximately fourfold increase in shear stiffness. This was adequately supported by simple modeling. Manufacture can be automated without disproportionally large waste or time consumption. The compressional stiffness will inevitably be significantly reduced, compared to a $90^{\circ}$ grain-to-plane angle.

The fracture morphology has not been the primary issue of the present investigation, but studies of the failed specimens indicate that stacking at alternating angles $\pm \alpha$ increases 
the resilience, as the fibres of crossing layers of balsa core tend to bridge across transverse core cracks.

\section{References}

1. Zenkert (editor), “The Handbook of Sandwich Construction”, EMAS, 1997, ISBN 0947817964

2. Tagarielli, V. L., Deshpande, V. S., Fleck, N. A., ”The high strain rate response of PVC foams and end-grain balsa wood”, Composites Part B, Vol. 39, 2008, pp. 83-91

3. Bekisli, B. and Grenestedt, J., ”Experimental Evaluation of Balsa Sandwich Core with Improved Shear Properties", Composites Science and Technology Vol. 64 No. 5, April 2004,pp. 667-674

4. Liu, T., Deng, Z. C., Lu, T. J. Design Optimization of truss-cored sandwiches with homogenization, International Journal of Solids and Structures, Vol. 43 pp. $7891-7918,2006$

5. Wicks, N. and Hutchinson, J. W., "Optimal truss plates”, International Journal of Solids and Structures, Vol. 38 pp. 5165-5183, 2001

6. Wicks, N. and Hutchinson, J. W., "Performance of sandwich plates with truss cores”, Mechanics of Materials, Vol. 36 pp. 739-751, 2004

7. Jones, R. M., "Mechanics of Composite Materials", McGraw-Hill 1975, ISBN 0-07-032790-4 
8. Gibson, L. J., Ashby, M. F., "Cellular Solids - Structure \& Properties”, Pergamon Press, Oxford, 1988, ISBN 0-08-036607-4

9. Strand, R, “Wet Balsa Core”, Professional Boatbuilder, Number 96, August/September 2005 